\title{
Importance of cooling rate and animal variability for boar sperm cryopreservation: insights from the cryomicroscope
}

\author{
A. Medrano ${ }^{1,2 *}$, P. F. Watson ${ }^{1}$ and W. V. Holt ${ }^{2}$ \\ ${ }^{1}$ Department of Veterinary Basic Sciences, Royal Veterinary College, Royal College Street, \\ London NW1 OTU, UK; and ${ }^{2}$ Institute of Zoology, The Zoological Society of London, \\ Regents Park, London NW1 4RY, UK
}

A series of experiments was set up to investigate the effect of different cooling rates on boar sperm cryosurvival using cryomicroscopy. The cooling protocols were split into two stages: (i) from $+5^{\circ} \mathrm{C}$ to $-5^{\circ} \mathrm{C}$ and (ii) from $-5^{\circ} \mathrm{C}$ to $-50^{\circ} \mathrm{C}$. Fluorescent probes (SYBR14 and propidium iodide) were used to monitor plasma membrane integrity during the entire process. Cooling rates in the range $3^{\circ} \mathrm{C} \mathrm{min}^{-1}$ to $12^{\circ} \mathrm{C} \mathrm{min}^{-1}$ did not cause significant damage to the sperm plasma membrane between $+5^{\circ} \mathrm{C}$ and $-5^{\circ} \mathrm{C}$; however, spermatozoa cooled at $24^{\circ} \mathrm{C} \mathrm{min}{ }^{-1}$ to $-5^{\circ} \mathrm{C}$ were slightly damaged. Motility was not particularly sensitive to variations in cooling rate. Cooling rates in the range $15^{\circ} \mathrm{C} \mathrm{min}-1$ to $60^{\circ} \mathrm{C} \mathrm{min}^{-1}$ did not produce differences in sperm cryosurvival during freezing between $-5^{\circ} \mathrm{C}$ and $-50^{\circ} \mathrm{C}$, or after thawing. In addition, cooling rates in the range $3^{\circ} \mathrm{C} \mathrm{min}{ }^{-1}$ to $80^{\circ} \mathrm{C} \mathrm{min}^{-1}$ did not produce significant differences in sperm cryosurvival. However, slow freezing $\left(3^{\circ} \mathrm{C} \mathrm{min}-1\right)$ induced a slight increase in the percentage of plasma membrane-damaged spermatozoa (propidium iodide-positive) at $-50^{\circ} \mathrm{C}$. Inter-ejaculate and inter-boar differences in sperm cryosurvival were manifested independently of cooling rate. The sperm plasma membrane remained intact (SYBR14-positive) during cooling and freezing, but upon rewarming, the plasma membrane of a high proportion of spermatozoa was damaged (propidium iodide-positive), indicating that rewarming is a critical step of the freezing-thawing process.

\section{Introduction}

Spermatozoa experience physical and chemical stresses during cooling and freezing as a result of ice formation and osmotic changes in the medium. Sperm cryosurvival appears to depend on intrinsic properties of the sperm plasma membrane, such as biochemical composition, thermal behaviour, osmotic resistance and the physical stresses determined by the protocol (Hammerstedt et al., 1990; De Leeuw et al., 1991). Sperm survival in such conditions can be modified by the rate at which they are cooled (Fiser and Fairfull, 1990; Bwanga et al., 1991). The optimal cooling rate leading to initial ice formation has been identified as being between $3^{\circ} \mathrm{C} \mathrm{min}-1$ and $5^{\circ} \mathrm{C} \mathrm{min}^{-1}$, whereas during the freezing process itself, a faster rate

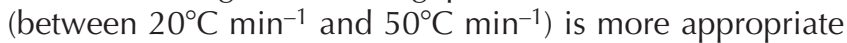
(Fiser and Fairfull, 1990; Bwanga et al., 1991; Fiser, 1991). However, there are complex interactions between cooling rate, glycerol concentration and warming rates, which produce different responses in sperm survival (Fiser, 1991;

*Present address: Department of Animal Sciences, Faculty of Superior Studies-Cuautitlan, National Autonomous University of Mexico (UNAM), Km 2.5 Carretera Cuautitlan-Teoloyucan, Cuautitlan, Izcalli 54700, Mexico

Email: amedrano@servidor.unam.mx
Fiser et al., 1993). Variation in individual males in the response of spermatozoa to different cooling rates overshadows these factors; however, individual variability due to freezing protocols appears to have been minimized by some researchers who have selected boars on the basis of their cryoresistance; this is usually called 'freezability' (Almid et al., 1989; Berger and Fischerleitner, 1992). As a consequence, the effects of cooling rate have not been assessed comparatively between individuals whose spermatozoa are either particularly resistant or susceptible (the so-called 'good' and 'bad freezers') to cryopreservation. The source of this variation is unknown, but appears to involve both freezing protocol-sensitive and -non-sensitive sperm characteristics. Optimization of the freezing protocol may reduce some of the variability, thereby exposing the non-sensitive aspects. Thus, the origin of boar variation may become more amenable to investigation .

Traditional approaches to the study of sperm cryosurvival, based mainly on assessments after thawing, have provided valuable knowledge about the factors that affect sperm injury during freezing and thawing. However, since the advent of cryomicroscopy, important insights have been gained into the special conditions that spermatozoa experience at freezing temperatures. The cryomicroscope permits direct and continuous viewing of spermatozoa, while the temperature is controlled accurately, so that different cooling and warming rates can be tested to 
investigate the effects of temperature variation. The use of fluorescent probes, on the basis of membrane permeability, has allowed the detection of distinctive subpopulations that can be quantified easily by fluorescence microscopy or flow cytometry. Furthermore, we have developed the use of the fluorescent probes SYBR14 and propidium iodide for cryomicroscopy to monitor plasma membrane integrity continuously during freezing and thawing.

The hypothesis underlying the present study was that ejaculates from different boars require different cooling rates for optimal sperm cryosurvival. This requirement could arise if differences in sperm membrane biochemistry and structure caused corresponding differences, for example, in water permeability, hence changing the optimal cooling rates.

\section{Materials and Methods}

\section{Source and preparation of semen}

Semen was collected by the gloved hand method from boars housed at commercial artificial insemination centres and sent undiluted by mail packaged in insulated containers at ambient temperature. Semen arrived at its destination after 16-20 h.

Before cryomicroscopy, the semen was filtered through gauze and centrifuged for $10 \mathrm{~min}$ at $500 \mathrm{~g}$. Seminal plasma was removed by aspiration and the spermatozoa were resuspended in up to half of the final volume in standard BF5 freezing medium (Pursel and Johnson, 1975), without glycerol, at room temperature.

The criterion for selecting the semen samples to be used in these experiments was that motility before freezing (after removal of seminal plasma and resuspension in BF5 freezing medium) was at least $70 \%$ of motile cells; the corresponding proportion of live cells (SYBR14-positive) in these samples was about $80 \%$.

Sperm suspensions were cooled over $2 \mathrm{~h}$ to $5^{\circ} \mathrm{C}$ (approximately $0.2^{\circ} \mathrm{C} \mathrm{min}-1$ ) and BF5 medium with glycerol (final concentration $1 \%(\mathrm{v} / \mathrm{v})$ ) was added. The final sperm concentration was approximately $5.0 \times 10^{7}$ spermatozoa $\mathrm{ml}^{-1}$. SYBR14 (5 $\mu \mathrm{l}$; diluted to $100 \mathrm{nmol} \mathrm{I}^{-1}$ in BF5) and $5 \mu \mathrm{l}$ propidium iodide $\left(12 \mu \mathrm{mol} \mathrm{I}^{-1}\right)$ were added to the diluted spermatozoa as live and dead reporter probes, respectively (Molecular Probes, Oregon).

\section{Cryomicroscopy}

The cryomicroscope used for this work comprised a Zeiss Axioskop (Carl Zeiss, Oberkochen) with cryostage (CM-3 Planer; Biomed, Sunbury-on-Thames), equipped with phase contrast, Nomarski and fluorescence facilities. A Hamamatsu (C2400 SIT) low-light video camera and a JVC video recorder were used to record experimental observations for subsequent detailed analysis.

Samples of spermatozoa were examined within glass chambers that were placed on the cryostage. This step enabled the spermatozoa to be recovered from the cryomicroscope after thawing for assessment of motility. The internal chamber dimensions were: length $=1.0 \mathrm{~cm}$; width $=0.5 \mathrm{~cm}$; depth $=20 \mu \mathrm{m}$; and volume $=10 \mu \mathrm{l}$. Chambers were made using glass coverslips.

\section{Validation of the chamber}

Use of the chambers was validated to determine whether there was a temperature difference between the sample and the cooling surface. The chamber, containing pure water, was positioned over the temperature-sensing thermocouple at $30^{\circ} \mathrm{C}$ and was cooled (i) to $-5^{\circ} \mathrm{C}$ at $6^{\circ} \mathrm{C} \mathrm{min}-1$ and (ii) to $-15^{\circ} \mathrm{C}$ at $30^{\circ} \mathrm{C} \mathrm{min}^{-1}$, and rewarmed to $30^{\circ} \mathrm{C}$ at $60^{\circ} \mathrm{C} \mathrm{min}^{-1}$. The protocols were performed in triplicate and recorded on video. The freezing point of water was estimated from the cryomicroscope readouts from the video recordings. A small difference between the freezing point of pure water put directly over the thermocouple $\left(0^{\circ} \mathrm{C}\right)$ and put into the chamber $\left(-1.80 \pm 1.01^{\circ} \mathrm{C}\right.$, mean \pm SEM $)$ was detected. Subsequent data were temperature-corrected where appropriate.

\section{Staining procedure}

SYBR14 penetrates both intact and damaged membranes, producing green fluorescence in the sperm nucleus. Propidium iodide permeates through damaged membranes only, producing red fluorescence. When the plasma membrane loses integrity, propidium iodide penetrates to the nucleus and quenches or displaces SYBR14, with a resultant change in colour (Garner and Johnson, 1995).

For the cryomicroscope experiments, the ratio of intact (SYBR14-positive) and damaged (propidium iodide-positive) sperm membranes was estimated for each sample at the beginning of each experiment. Fluorescent spermatozoa viewed by cryomicroscopy are shown (Fig. 1). However, in subsequent steps of the procedure only the propidium iodide-positive subpopulation was monitored (about 20\% of the total number of cells, mean $n=37$ per field of view). Changes in the number of permeable cells (propidium iodide-positive) were observed within the same field of view. The number of permeable cells was estimated from video recordings of single fields illuminated with rhodamine optics, and made using a low light video camera (Hamamatsu C2400 SIT camera) by fluorescence microscopy. Propidium iodide-positive spermatozoa were recorded on video at +5 , -5 and $30^{\circ} \mathrm{C}$.

\section{Assessment of motility}

The percentage of motile spermatozoa was assessed from video recordings with the aid of the Hobson Sperm Tracker and subjective assessment. Motile spermatozoa were recorded on video from a phase contrast microscope (Olympus $\mathrm{BH}-2$ ) equipped with a warm stage at $39^{\circ} \mathrm{C}$ using a $\times 20$ objective (negative-high phase contrast), projector lens $\times 3$. 3 Pulnix TM-6CN video camera and a JVC video recorder, at 2 min after rewarming. 


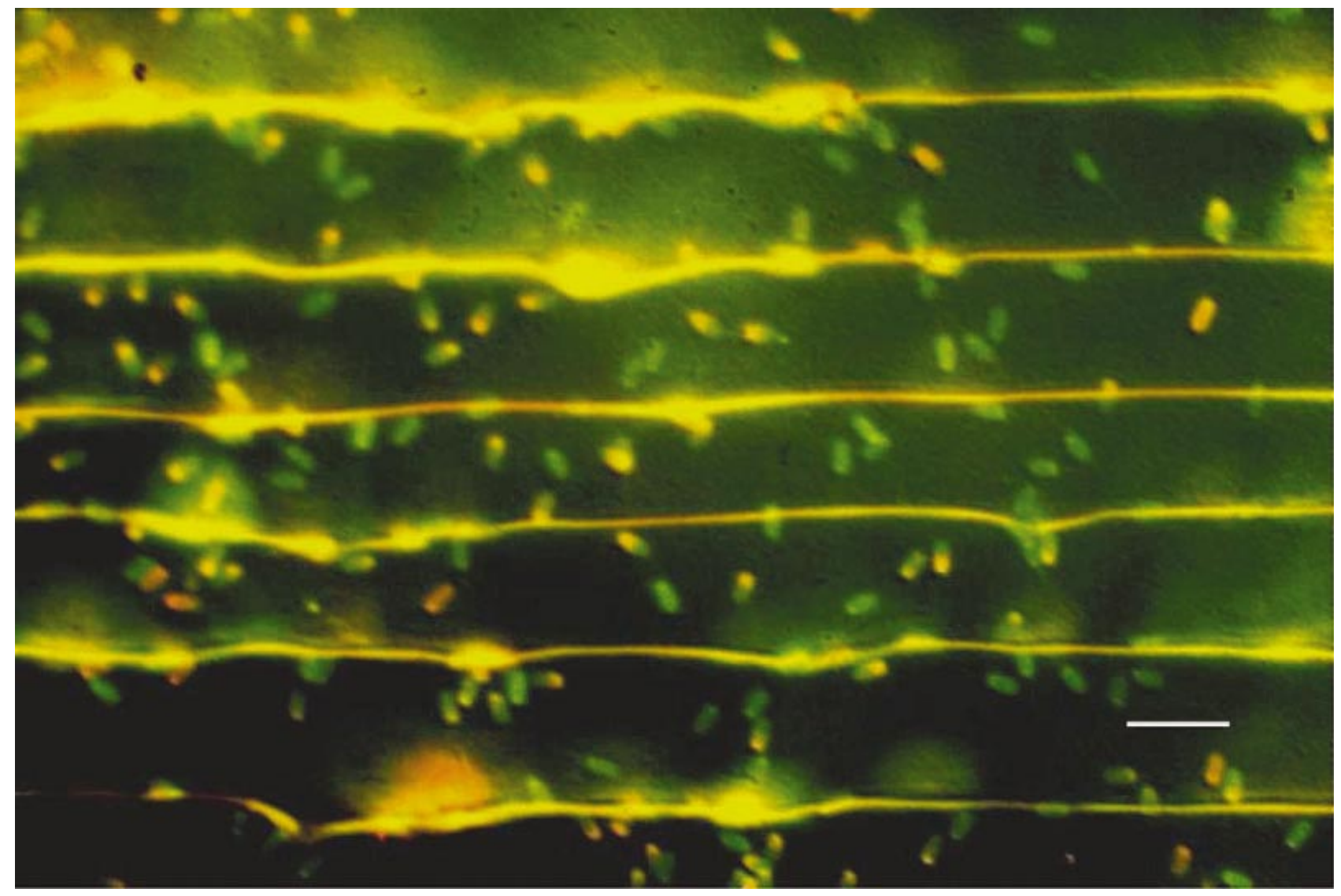

Fig. 1. Micrograph showing fluorescent boar spermatozoa in ice (green: SYBR14-positive; red: propidium iodide-positive) diluted in BF5 medium viewed by cryomicroscopy at $-20^{\circ} \mathrm{C}$. Scale bar represents $20 \mu \mathrm{m}$.

\section{Statistical analysis}

A Wilcoxon matched-pairs test was used to make sequential paired comparisons between counts of propidium iodide-positive cells at the successive steps of the experimental process in the cryomicroscope: at $30^{\circ} \mathrm{C}, 0^{\circ} \mathrm{C}$ and at the beginning of the incubation period (Expt 1), at $+5,-5$ and $30^{\circ} \mathrm{C}$ (Expt 3a) and at $+5,-5,-50$ and $30^{\circ} \mathrm{C}$ (Expt 3b).

Friedman ANOVA was used to examine the effects of cooling rates between counts of propidium iodide-positive cells at each $20 \mathrm{~s}$ interval during the 3 min incubation period in Expt 1. The number of propidium iodide-positive cells was normalized by regarding the number of permeable cells at the end of the incubation period (fully permeabilized) as $100 \%$. Successive estimates were regarded as proportional.

The Kruskal-Wallis ANOVA by Ranks was used to examine the effect on cooling rate of the final increase (after rewarming) in the number of propidium iodide-positive spermatozoa. The counts were normalized by regarding the number of propidium iodide-positive spermatozoa at the beginning of each treatment sequence as $100 \%$. Successive estimates were regarded as proportions.

All treatments (Expt 1: warming rates and incubation temperatures; Expt 3: cooling rates) were performed in duplicate and in random order.

Percentages of motile spermatozoa were examined by ANOVA after arcsine transformation of the data.

\section{Experiment 1: validation of the cryomicroscopy technique}

The aim of this experiment was to validate the concept that sperm membrane permeability could be monitored continuously during freezing-thawing protocols in real time (cryomicroscopy). The fluorescent probes SYBR14 and propidium iodide were used as reporters of plasma membrane integrity. Spermatozoa were deliberately coldshocked $\left(30^{\circ} \mathrm{C} \mathrm{min}^{-1}\right)$ and rewarmed to see how rapidly they became propidium iodide-positive.

Semen samples diluted in BF5 from six boars (replicates) were cooled from $30^{\circ} \mathrm{C}$ to $0^{\circ} \mathrm{C}$ at $30^{\circ} \mathrm{C} \mathrm{min}-1$, kept for $40 \mathrm{~s}$ at $0^{\circ} \mathrm{C}$ and warmed either (i) at $30^{\circ} \mathrm{C} \mathrm{min}^{-1}$ to $10^{\circ} \mathrm{C}$ or (ii) at $75^{\circ} \mathrm{C} \mathrm{min}{ }^{-1}$ to $25^{\circ} \mathrm{C}$; the samples were then held for $3 \mathrm{~min}$ at the target temperatures. The two warming rates were chosen so that the time taken to reach the two different target temperatures was equal: $20 \mathrm{~s}$ to reach $10^{\circ} \mathrm{C}$ or $25^{\circ} \mathrm{C}$. Propidium iodide-positive spermatozoa were recorded on 
video at (i) $30^{\circ} \mathrm{C}$, (ii) $0^{\circ} \mathrm{C}$ and (iii) at the beginning of the incubation period $\left(10^{\circ} \mathrm{C}\right.$ or $\left.25^{\circ} \mathrm{C}\right)$.

\section{Experiment 2: effect of SYBR14 and propidium iodide on sperm motility}

The aim of this experiment was to identify possible adverse effects of the fluorescent compounds on sperm motility.

Semen samples from five boars (replicates) were diluted in BF5 $\left(5.0 \times 10^{7}\right.$ spermatozoa $\left.\mathrm{ml}^{-1}\right)$ for this experiment. Aliquots of diluted spermatozoa $(1.0 \mathrm{ml})$ were cooled from room temperature to $+5{ }^{\circ} \mathrm{C}$ at $0.2^{\circ} \mathrm{C} \mathrm{min}-1$ in (i) the presence or (ii) the absence of SYBR14 and propidium iodide.

Motility was assessed (i) immediately after cooling over a period of $2 \mathrm{~h}$ (after adding the glycerolated extender) and (ii) after 1 or $2 \mathrm{~h}$ of storage at $+5^{\circ} \mathrm{C}$.

\section{Experiment 3: comparison of inter-ejaculate sperm responses to different cooling rates in the cryomicroscope}

This experiment was set up to investigate and compare the inter-ejaculate sperm responses to different cooling rates, using the range of temperatures that precede ice formation and the temperatures experienced during freezing.

Initial cooling rate from $+5^{\circ} \mathrm{C}$ to $-5^{\circ} \mathrm{C}$. Spermatozoa from five boars (replicates) diluted in BF5 medium and stained with SYBR14 and propidium iodide were cooled in chambers from $+5^{\circ} \mathrm{C}$ to $-5^{\circ} \mathrm{C}$ on the stage of the cryomicroscope at: (i) 3, (ii) 6, (iii) 12 and (iv) $24^{\circ} \mathrm{C} \mathrm{min}^{-1}$ and held for $2.0 \mathrm{~min}$ at $-5^{\circ} \mathrm{C}$. All treatments were rewarmed to $30^{\circ} \mathrm{C}$ at $60^{\circ} \mathrm{C} \mathrm{min}-1$ and held for $2.0 \mathrm{~min}$. Propidium iodide-positive spermatozoa were recorded on video at (i) +5 , (ii) -5 and (iii) $30^{\circ} \mathrm{C}$.

Samples were recovered from the cryomicroscope and transferred to a phase-contrast microscope equipped with a warm stage at $39^{\circ} \mathrm{C}$ to record the sperm motility on video.

After ice formation cooling rates from $-5^{\circ} \mathrm{C}$ to $-50^{\circ} \mathrm{C}$. Two ranges of cooling rate were examined separately: from $15^{\circ} \mathrm{C} \mathrm{min}-1$ to $60^{\circ} \mathrm{C} \mathrm{min}^{-1}$, and from $3^{\circ} \mathrm{C} \mathrm{min}^{-1}$ to $80^{\circ} \mathrm{C}$ min $^{-1}$.

Twenty ejaculates from 13 boars (replicates) were tested in the range $15^{\circ} \mathrm{C} \mathrm{min}-1$ to $60^{\circ} \mathrm{C} \mathrm{min}-1$ and one ejaculate (in duplicate) from each of five boars was examined in the range $3^{\circ} \mathrm{C} \mathrm{min}^{-1}$ to $80^{\circ} \mathrm{C} \mathrm{min}^{-1}$. Samples $(5 \mu \mathrm{l})$ of spermatozoa in BF5 medium containing SYBR14 and propidium iodide were dispensed into chambers, placed on the cryomicroscope stage, cooled from $+5^{\circ} \mathrm{C}$ to $-5^{\circ} \mathrm{C}$ at $6^{\circ} \mathrm{C} \mathrm{min}-1$, and held for $2 \mathrm{~min}$.

Samples were cooled further from $-5^{\circ} \mathrm{C}$ to $-50^{\circ} \mathrm{C}$ at 15 , 30 and $60^{\circ} \mathrm{C} \mathrm{min}^{-1}$ (first range), at 3,30 and $80^{\circ} \mathrm{C} \mathrm{min}-1$ (second range), held for $2 \mathrm{~min}$ at $-50^{\circ} \mathrm{C}$, and then rewarmed

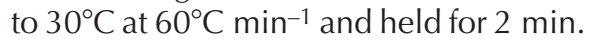

Propidium iodide-positive cells were recorded on video at $+5,-5$ and $30^{\circ} \mathrm{C}$. Propidium iodide-positive cells at $-50^{\circ} \mathrm{C}$ were counted by direct observation on the cryomicroscope because the ice pattern at that temperature caused too much brightness, thereby precluding accurate counting from video recordings.

Samples were recovered from the cryomicroscope and transferred to a phase-contrast microscope equipped with a warm stage at $39^{\circ} \mathrm{C}$ to record the sperm motility on video.

\section{Results}

\section{Experiment 1}

Cold shock (cooling from $30^{\circ} \mathrm{C}$ to $0^{\circ} \mathrm{C}$ in $1 \mathrm{~min}$ ) significantly increased $(P<0.001)$ the number of propidium iodide-positive cells. Rewarming from $0^{\circ} \mathrm{C}$ to $10^{\circ} \mathrm{C}$ did not significantly increase the proportion of propidium iodidepositive spermatozoa when glycerol was absent, but did when glycerol was present $(P<0.005)$. The proportion of propidium iodide-positive cells increased when spermatozoa were rewarmed to $25^{\circ} \mathrm{C}$ in the absence of glycerol $(P<0.05)$ (Fig. 2). Incubation for $3 \mathrm{~min}$ at $10^{\circ} \mathrm{C}$ and at $25^{\circ} \mathrm{C}$ failed to induce further permeabilization, regardless of whether glycerol was present.

\section{Experiment 2}

SYBR14 and propidium iodide did not affect the proportion of motile spermatozoa: there was no difference in the percentage of motile cells, whether in the absence or presence of stain $(77.7 \pm 4.8 \%$ and $76.1 \pm 5.2 \%$, mean \pm SEM) after cooling for $2 \mathrm{~h}$ and after subsequent storage for 1 or 2 h (Table 1$)$.

\section{Experiment 3}

Initial cooling rate from $+5^{\circ} \mathrm{C}$ to $-5^{\circ} \mathrm{C}$. Cooling from $+5^{\circ} \mathrm{C}$ to $-5^{\circ} \mathrm{C}$ on the cryomicroscope at 3,6 and $12^{\circ} \mathrm{C} \mathrm{min}^{-1}$ did not result in a significant increase in membrane permeability. A slight increase was induced at $24^{\circ} \mathrm{C} \mathrm{min}^{-1}$ but, although significant $(P<0.02)$, the effect was small. Comparisons between the number of propidium iodidepermeable cells at $-5^{\circ} \mathrm{C}$ and at $30^{\circ} \mathrm{C}$ showed significant increases $(P<0.005)$ at all the rates tested (Fig. 3). The percentage of motile spermatozoa at rewarming was not different between boars or rewarming rates; however, one of the boars showed a different pattern of response from the others (Fig. 4).

Rate of cooling from $-5^{\circ} \mathrm{C}$ to $-50^{\circ} \mathrm{C}$, range $15^{\circ} \mathrm{C} \mathrm{min}^{-1}$ to $60^{\circ} \mathrm{C} \mathrm{min}^{-1}$. The number of propidium iodide-permeable cells was constant during the cooling and freezing phase of the protocol, irrespective of cooling rate (Fig. 5). A highly significant increase in the number of propidium iodidepermeable cells after rewarming to $30^{\circ} \mathrm{C}$ was observed at the three rates tested $(P<0.0001)$. The percentage increase assessed at rewarming was not different among the three rates.

Motility data were analysed to compare the interejaculate variability. Significant inter-sample (ejaculate) 

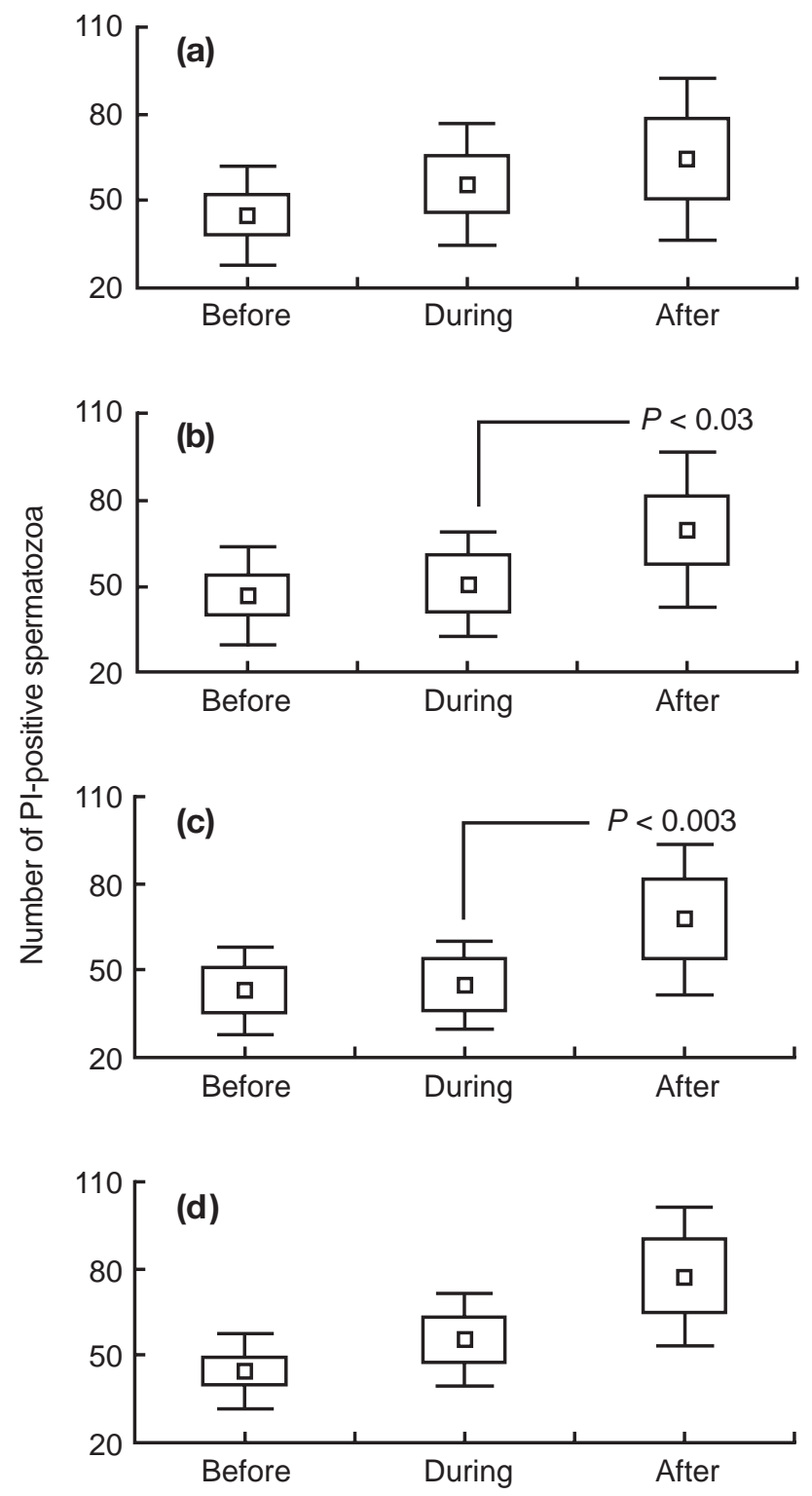

Fig. 2. Changes in the number of propidium iodide (PI)-positive boar spermatozoa before $\left(30^{\circ} \mathrm{C}\right)$, during $\left(0^{\circ} \mathrm{C}\right)$ and after $\left(10^{\circ} \mathrm{C}(\mathrm{a}, \mathrm{C})\right.$ or $\left.25^{\circ} \mathrm{C}(\mathrm{b}, \mathrm{d})\right)$ cold shock in the presence $(\mathrm{c}, \mathrm{d})$ or absence $(\mathrm{a}, \mathrm{b})$ of glycerol. Semen samples were cooled from $30^{\circ} \mathrm{C}$ to $0^{\circ} \mathrm{C}$ at $30^{\circ} \mathrm{C} \mathrm{min}{ }^{-1}$, held for $40 \mathrm{~s}$ at $0^{\circ} \mathrm{C}$ and warmed at either $(\mathrm{a}, \mathrm{C})$ $30^{\circ} \mathrm{C} \mathrm{min}^{-1}$ to $10^{\circ} \mathrm{C}$ or $(\mathrm{b}, \mathrm{d}) 75^{\circ} \mathrm{C} \mathrm{min}^{-1}$ to $25^{\circ} \mathrm{C}$. Boxes are standard error of the mean and lines are standard deviation.

differences in motility were detected $(P<0.0001)$, but neither the effect of rate nor the ejaculate $\times$ rate interaction was significant.

Motility data were analysed to compare the interejaculate variability. For this purpose, only two boars, for which multiple ejaculate data were available, were included in the ANOVA. Although a significant intra-boar (inter-ejaculate) effect was detected, the analysis revealed
Table 1. Percentage of motile unstained and stained boar spermatozoa after slow cooling to $+5^{\circ} \mathrm{C}$, and subsequent storage for 1 or $2 \mathrm{~h}$

\begin{tabular}{lcccc}
\hline Treatment & Cooled & 1 h storage & 2 h storage & Mean \\
\hline Unstained & 76.3 & 80.6 & 76.3 & 77.7 \\
Stained & 76.3 & 78.8 & 73.2 & 76.1 \\
Mean & 76.3 & 79.7 & 74.7 & SE $=4.7^{*}$
\end{tabular}

*SE was calculated from the pooled SD.
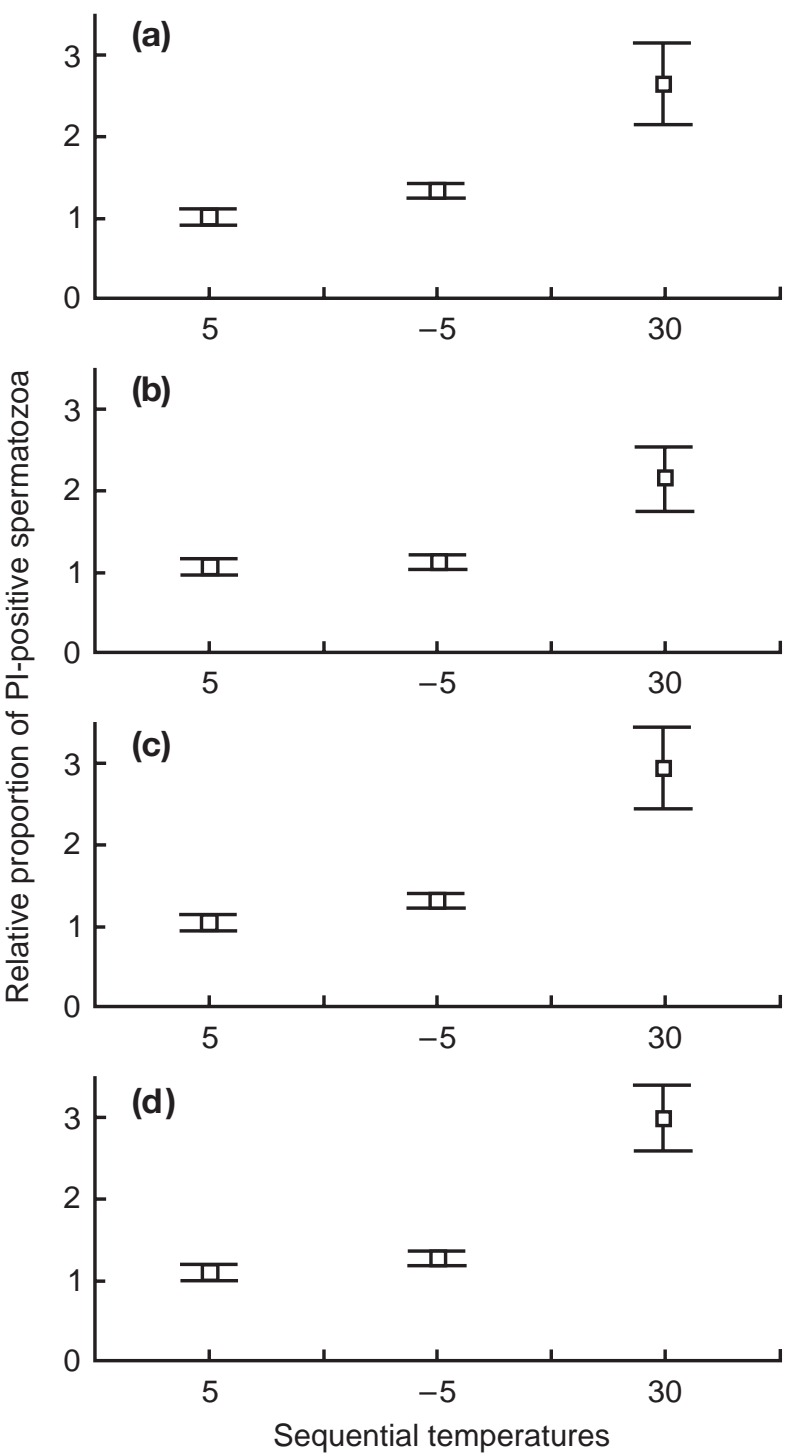

Fig. 3. Increase in the percentage of propidium iodide (PI)-positive boar spermatozoa during cooling and rewarming. Spermatozoa from five boars were cooled from $+5^{\circ} \mathrm{C}$ to $-5^{\circ} \mathrm{C}$ at (a) 3, (b) 6, (c) 12

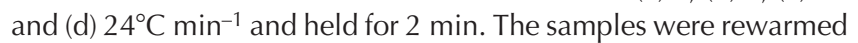
to $30^{\circ} \mathrm{C}$ at $60^{\circ} \mathrm{C} \mathrm{min}{ }^{-1}$ and held for $2 \mathrm{~min}$. Propidium iodide-positive spermatozoa were recorded on video at $+5,-5$ and $+30^{\circ} \mathrm{C}$. Values are means \pm standard error of mean. The number of propidium iodide-positive cells was normalized by regarding the number of propidium iodide-positive cells at the start of each treatment as $100 \%$. Successive estimates were regarded as proportions. 


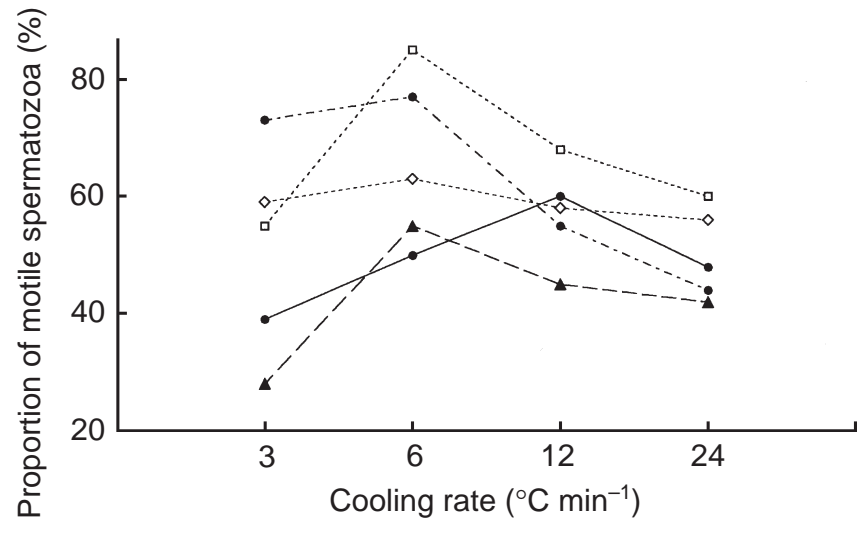

Fig. 4. Percentage of motile boar spermatozoa at rewarming. The effect of four cooling rates $\left(3,6,12\right.$ and $\left.24^{\circ} \mathrm{C} \mathrm{min}^{-1}\right)$ from $+5^{\circ} \mathrm{C}$ to $-5^{\circ} \mathrm{C}$ in the cryomicroscope. Data are from five boars; one ejaculate (in duplicate) was collected from each boar. Values are means; standard errors were omitted for clarity (SEM $=6.13)$.

that the inter-boar effect was far more important. This was confirmed by using the intra-boar (inter-ejaculate) mean square as an error term for the calculation of the inter-boar main effect $(P<0.0003)$. Despite the inter-ejaculate variation, ejaculates $(n=3)$ from boar number 1 showed similar cryosurvival in different weeks; that is, they had relatively high values of motility after freezing. Ejaculates $(n=6)$ from boar number 2 always had relatively low motility values.

Cooling rates from $-5^{\circ} \mathrm{C}$ to $-50^{\circ} \mathrm{C}$, range $3^{\circ} \mathrm{C} \mathrm{min}^{-1}$ to

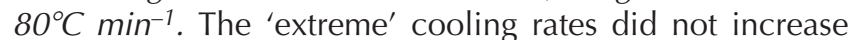
the proportion of propidium iodide-positive spermatozoa from different ejaculates significantly compared with the so-called 'optimal' rate of $30^{\circ} \mathrm{C} \mathrm{min}^{-1}$. After thawing, the percentage of motile spermatozoa differed between ejaculates $(P<0.0001)$; three ejaculates had very low motility values after freezing-thawing. The ejaculate $\times$ rate interaction was significant $(P<0.01)$, but the effect was attributed to two ejaculates; the effect of cooling rate was not significant.

\section{Discussion}

The use of fluorescent probes enabled the rapid detection of changes in sperm membrane permeability during cryomicroscopy and there was no adverse effect on sperm motility. The technique was considered to be a reliable method for routine use, offering rapid response times for identifying the critically damaging processes and periods during cryopreservation. Other workers have used cryomicroscopy as a method to assess sperm freezability, using bulk freezing as a control (Penfold et al., 1998); little discrepancy was found between the two methods. Furthermore, Mohammed and Moore (1995) studied freezing of human spermatozoa during cryomicroscopy with the aid of fluorescent stains; they were able to establish

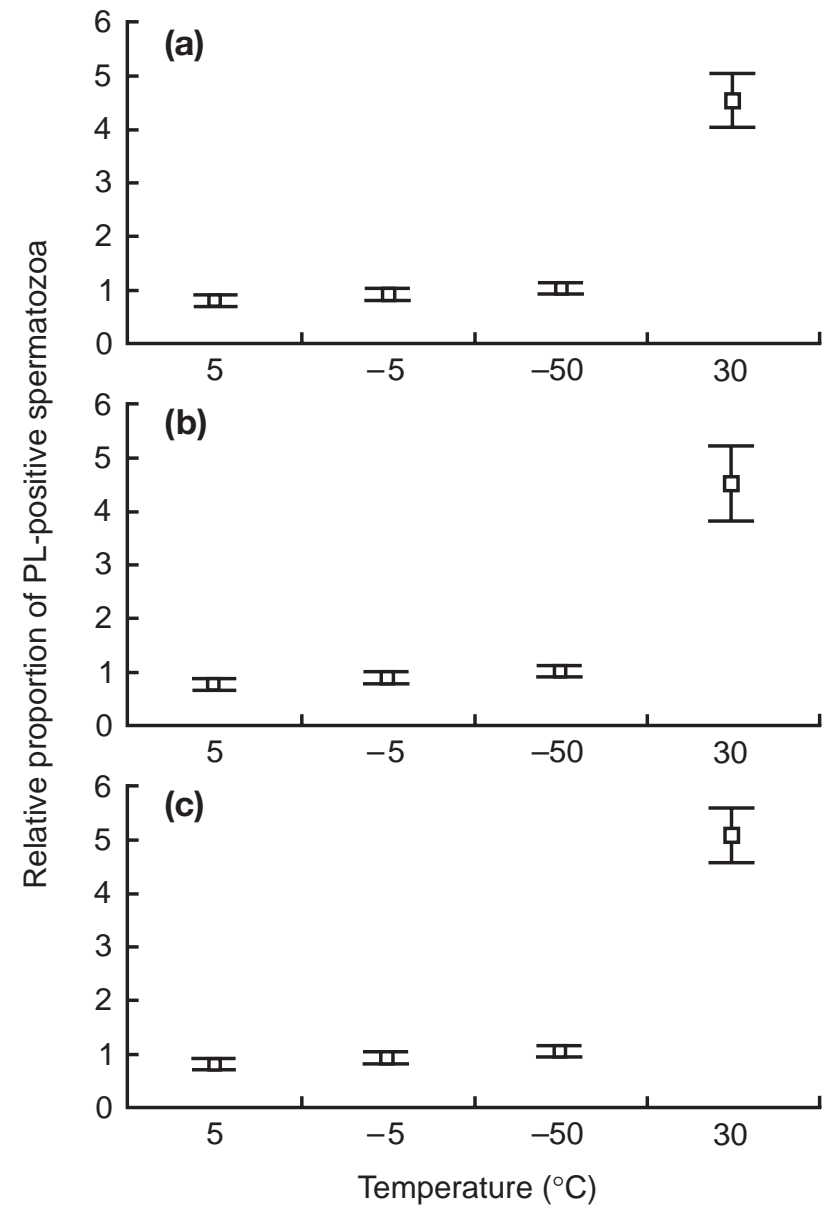

Fig. 5. Proportional increase in propidium iodide (PI)-positive boar spermatozoa during freezing and at rewarming. Samples were cooled from $+5^{\circ} \mathrm{C}$ to $-5^{\circ} \mathrm{C}$ at $6^{\circ} \mathrm{C} \mathrm{min}{ }^{-1}$ and held for $2 \mathrm{~min}$. The samples were cooled further from $-5^{\circ} \mathrm{C}$ to $-50^{\circ} \mathrm{C}$ at (a) 15 , (b) 30 or (c) $60^{\circ} \mathrm{C} \mathrm{min}-1$, held for $2 \mathrm{~min}$ at $-50^{\circ} \mathrm{C}$, and then rewarmed to $30^{\circ} \mathrm{C}$ at $60^{\circ} \mathrm{C} \mathrm{min}-1$ and held for $2 \mathrm{~min}$. Values are means \pm standard error of mean. Propidium iodide-positive cells were counted on video at $+5,-5$ and $+30^{\circ} \mathrm{C}$. Propidium iodide-positive cells at $-50^{\circ} \mathrm{C}$ were counted by direct observation on the cryomicroscope. Values were normalized by regarding the number of propidium iodide-positive cells at the start of each treatment as $100 \%$. Successive estimates were regarded as proportions.

a number of important temperatures during freezing-thawing, such as the temperature at which the spermatozoa stopped moving, the temperature at which the sperm suspension froze and thawed, and the temperature at which spermatozoa regained movement at rewarming.

Cold-shock experiments produced interesting results: rewarming to $10^{\circ} \mathrm{C}$ increased the number of propidium iodide-positive spermatozoa when glycerol was present but not when glycerol was absent.

Undertaking this experiment inevitably involved confounding either the rewarming rate or the time taken to reach the target temperature. In this case, the time to target temperature was made equal by varying the rewarming rate. 
Therefore, it could be argued that permeabilization was induced by the faster warming rate; however, it is more likely that permeabilization was induced because the temperature increased through a range known to induce lipid phase transitions and membrane destabilization. These effects may be attributable to a protective effect of glycerol against cold-shock, the damage only becoming apparent during rewarming. In the absence of glycerol, rewarming effects might be undetectable if a high proportion of cells had already been permeabilized during the cooling process.

Integrity of sperm plasma membranes was maintained during freezing, whereas disruption of the plasma membrane occurred, or was manifested, only after thawing. This might be due to the slow SYBR14 and propidium iodide diffusion rates at low temperatures or because the severe shrinkage to which cells are subjected during freezing prevents diffusion of propidium iodide through the sperm plasma membrane. However, we have observed spermatozoa becoming propidium iodide-positive during cryomicroscopy at temperatures as low as $-20^{\circ} \mathrm{C}$.

The cooling process was split into two stages to study the effects of cooling rate on the inter-ejaculate sperm responses: (i) before ice formation and (ii) after ice formation, on the basis of the events occurring around these processes. Before ice formation, cooling rates in the range $3^{\circ} \mathrm{C} \mathrm{min}^{-1}$ to

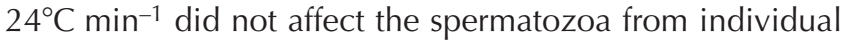
ejaculates consistently. The fastest cooling rate $\left(24^{\circ} \mathrm{C} \mathrm{min}-1\right)$ was identified as harmful. This observation may be interpreted as a continuation of the cold-shock process, in which changes in membrane architecture, involving lipid-phase transitions, induce plasma membrane damage (Crowe et al., 1989).

During the second stage of cooling, after ice formation, control of cooling rate is usually considered to be more important than it is before ice formation. Many workers have identified an 'optimal' cooling rate, the value of which lies between $20^{\circ} \mathrm{C} \mathrm{min}-1$ and $50^{\circ} \mathrm{C} \mathrm{min}^{-1}$ (Almid et al., 1989; Fiser and Fairfull, 1990; Bwanga et al., 1991). However, in the present study it was observed that differences in sperm cryosurvival as a result of cooling rate in the range $3^{\circ} \mathrm{C} \mathrm{min}-1$ to $80^{\circ} \mathrm{C} \mathrm{min}^{-1}$ were highly ejaculate-dependent. Therefore, the concept of an 'optimal' cooling rate has to be questioned. In support of this contention, theoretical simulations of intracellular water volume flux during cooling and warming indicated that boar spermatozoa responded similarly in the presence of glycerol and ethylene glycol at cooling rates in the range $10^{\circ} \mathrm{C} \mathrm{min}^{-1}$ to $100^{\circ} \mathrm{C} \mathrm{min}^{-1}$ (Gilmore et al., 1998).

Improvements in sperm cryosurvival have been reported when cooling rates are modified (for example, see Fiser and Fairfull, 1990). Such studies often do not consider individual boar differences in sperm freezability as a source of variation. The results of the present study show that spermatozoa from individuals considered as 'bad freezers' are relatively unaffected by adjustment of the cooling rate (they do not become 'good freezers'). In contrast, spermatozoa from 'good freezers' showed slightly better cryosurvival when frozen at faster cooling rates. At this point it is important to determine whether different ejaculates from the same individual, considered as either a 'good freezer' or a 'bad freezer', always perform as such. Although we recognize that this study was limited regarding the number of multiple ejaculates from the same boar, our evidence to date indicates that inter-ejaculate differences are considerably lower than inter-boar differences, indicating that this is a characteristic of boars rather than of the ejaculates. In support of this viewpoint, Thurston (2000) identified 'poor', 'average' and 'good' freezers after freezing and thawing five ejaculates from each of 129 boars.

These observations confirm anecdotal reports of interindividual differences in sperm cryosusceptibility in pigs. Although similar experiences have been reported for laboratory mice and rabbits (Nakagata and Takeshima, 1993), no explanations for these differences have been substantiated. A number of possible explanations may be useful in generating further hypotheses for investigating the underlying reasons for these observations.

Inter-species variation in sperm cryosusceptibility has been attributed to the marked differences in their total sperm and plasma membrane lipid compositions (DarinBennett and White, 1977). However, anatomical differences in the female reproductive tract and differences in the number of spermatozoa required for successful fertilization also determine the fertility of frozen semen. The question then arises as to whether such differences as occur within species also occur within individuals. Evidence from studies of domestic poultry supports the hypothesis that the differences have a genetic basis (Ansah and Buckland, 1982). Unfortunately, there is no comparable information about the lipid composition of sperm plasma membranes from different pig breeds or other mammalian genetic lines to corroborate the hypothesis that a genetic factor determines sperm cryosusceptibility.

In conclusion, cryomicroscopy has proven a useful method to study the effect of cooling rates on sperm cryosurvival. This technique enabled identification of rewarming as the critical step of freezing-thawing on the basis of monitoring the proportion of propidium iodidepositive cells at different stages of the process. Manipulation of the sperm plasma membrane composition to render it less susceptible to freezing-thawing stresses and study of genetic differences between 'good' and 'bad freezers' are important areas for further investigation.

A. Medrano was supported by a grant from the government of Mexico (CONACYT); the Association of Pig Al Centre Operators (UK) supported this work. The authors are grateful to JSR Healthbred Ltd, PIC International and Masterbreeders Ltd for supplying the boar semen used in this study.

\section{References}

Almid T, Clarke RN, Pursel VG and Johnson LA (1989) Effectiveness of in vitro methods for predicting in vivo fertilizing of boar spermatozoa cryopreserved with $2 \%$ or $4 \%$ glycerol Zuchthygiene 24 8-15 
Ansah GA and Buckland RB (1982) Genetic variation in fowl semen cholesterol and phospholipid levels and the relationship of these lipids with fertility of frozen-thawed and fresh semen Poultry Science 61 623-637

Berger B and Fischerleitner F (1992) On deep freezing of boar semen investigations on the effect of different straw volumes, methods of freezing and thawing extenders Reproduction in Domestic Animals 27 266-270

Bwanga CO, Einarsson S and Rodríguez-Martínez H (1991) Cryopreservation of boar semen. II: Effect of cooling rate and duration of freezing point plateau on boar semen frozen in mini- and maxi-straws and plastic bags Acta Veterinaria Scandinavica 32 455-461

Crowe JH, Hoekstra FA, Crowe LM, Anchordoguy TJ and Drobnis E (1989) Lipid phase transitions measured in intact cells with Fourier transform infrared spectroscopy Cryobiology 26 76-84

Darin-Bennett A and White IG (1977) Influence of the cholesterol content of mammalian spermatozoa on susceptibility to cold shock Cryobiology 14 466-470

De Leeuw F, Colenbrander B and Verkleij AJ (1991) The role membrane damage plays in cold shock and freezing injury Reproduction in Domestic Animals Supplement 1 95-104

Fiser PS (1991) Interactions of cooling velocity, warming velocity and glycerol on the survival of frozen-thawed boar sperm Reproduction in Domestic Animals Supplement 1 123-137

Fiser PS and Fairfull RW (1990) Combined effect of glycerol concentration and cooling velocity on motility and acrosomal integrity of boar spermatozoa frozen in $0.5 \mathrm{ml}$ straws Molecular Reproduction and Development 25 123-129

Fiser PS, Fairfull RW, Hansen C, Panich PL, Shresta J and Underrhill L (1993) The effect of warming velocity on motility and acrosomal integrity of boar sperm as influenced by the rate of freezing and glycerol level Molecular Reproduction and Development 34 190-195
Garner DL and Johnson LA (1995) Viability assessment of mammalian sperm using SYBR14 and propidium iodide Biology of Reproduction 53 276-284

Gilmore JA, Liu J, Peter AT and Critser JK (1998) Determination of plasma membrane characteristics of boar spermatozoa and their relevance to cryopreservation Biology of Reproduction 58 28-36

Hammerstedt RH, Graham JK and Nolan JP (1990) Cryopreservation of mammalian sperm: what we ask them to survive Journal of Andrology $1173-88$

Mohammed SN and Moore HDM (1995) An assessment of the cryomicroscope to study motility and viability changes due to cryopreservation protocols for human spermatozoa Cryobiology 32566 (Abstract)

Nakagata $\mathbf{N}$ and Takeshima T (1993) Cryopreservation of mouse spermatozoa from inbred and F1-hybrid strains Experimental Animals $42317-320$

Penfold LM, Garner DL, Donohue AM and Johnson LA (1997) Comparative viability of bovine sperm frozen on a cryomicroscope or in straws Theriogenology 47 521-530

Pursel VG and Johnson LA (1975) Freezing of boar spermatozoa: fertilizing capacity with concentrated semen and a new thawing procedure Journal of Animal Science 40 99-102

Thurston LM (2000) An Investigation into Sources of Variation and the Genetic Basis of Boar Spermatozoa Survival Following Cryopreservation PhD Thesis, University of London

Received 11 May 2001

First decision 28 June 2001.

Revised manuscript received 9 October 2001.

Accepted 17 October 2001. 